\begin{tabular}{|c|c|c|}
\hline 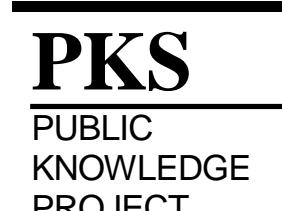 & $\begin{array}{c}\text { REVISTA DE GEOGRAFIA } \\
\text { (RECIFE) } \\
\text { Rtto://www.revistauffoe.br/revistageografia }\end{array}$ & $\begin{array}{l}\text { OJS } \\
\text { ODEN } \\
\text { JOURNAL } \\
\text { CYSTEMS }\end{array}$ \\
\hline
\end{tabular}

\title{
AS FEIRAS POPULARES NO NORDESTE BRASILEIRO: APORTES INICIAIS ${ }^{1}$
}

\author{
Luiz Antônio Araújo Gonçalves ${ }^{1}$; Virginia Célia Cavalcante Holanda²;
}

\author{
1 Professor Adjunto do Curso de Geografia da Universidade Estadual Vale do Acaraú - UVA. Email: \\ geoluiz@hotmail.com \\ ${ }^{2}$ Professora Adjunta do Curso de Geografia da Universidade Estadual Vale do Acaraú - UVA. Email: \\ virginiaholand@hotmail.com
}

Artigo recebido em 26/05/2016 e aceito em 13/08/2017

\begin{abstract}
RESUMO
O presente o artigo analisa as transformações que vêm ocorrendo nas feiras nordestinas. Busca-se apreender o conteúdo dessas transformações na perspectiva da sociedade e do espaço tendo como objeto de pesquisa as feiras de confecção que ocorrem nos municípios de Caruaru em Pernambuco; Feira de Santana na Bahia e Sobral no Ceará. Nas cidades do Nordeste, as feiras têm como principal característica, o comércio de rua situado, em geral, nas áreas centrais onde barracas são instaladas para abrigar os produtos comercializados. No passado, a dinâmica da cidade e da feira se fundia dada a importância dessa forma de comércio na construção do lugar e das práticas espaciais cotidianas. A grande concentração e fluxo de pessoas e mercadorias transformavam a fisionomia das cidades sertanejas, alterando o ritmo da vida citadina. Desse modo, a feira constituía uma centralidade por ser lócus de comercialização da produção regional atraindo pessoas do campo e de núcleos urbanos menores. Contudo, constata-se na atualidade uma verdadeira metamorfose da feira em sua forma e conteúdo evidenciado pela inserção maciça de produtos da indústria da confecção e vestuário.
\end{abstract}

Palavras-chave: Feiras, Nordeste, Transformações.

\section{THE POPULAR FAIRS IN NORTHEASTERN BRAZIL: INITIAL CONTRIBUTIONS}

\begin{abstract}
This article analyzes the changes that have occurred in the northeastern fairs. Seeks to grasp the content of these changes from the perspective of society and space having as research object the fairs of manufacture of garments that take place in municipalities; Caruaru in Pernambuco; Feira de Santana in Bahia and Sobral in Ceará. In the cities of the Northeast, the fairs have as main feature, street trading located generally in the central areas where tents are installed to house the products supplied. In the past, the dynamics of the city and the fair merged given the importance of this kind of trade in the construction of the place and the daily spatial practices. The great concentration and flow of people and goods transformed the physiognomy of region's cities, changing the space of city life. Thus, the fair was a centrality to be marketing locus of regional production attracting people from rural areas and smaller urban centers. However, it appears at present a true metamorphosis of the fair in form and content evidenced by the massive insertion of products of the clothing and apparel industry.
\end{abstract}

Keywords: Fairs, Northeastern, Transformation.

\footnotetext{
${ }^{1}$ Artigo apresenta alguns resultados da pesquisa intitulada: As feiras de confecção popular e novas geografias no Nordeste brasileiro, financiada pelo Edital Universal MCTI/CNPq No 14/2014. Pesquisa integrante do Grupo de Pesquisa (CNPq): Planejamento Urbano e Regional.

$\begin{array}{lll}\text { Gonçalves e Holanda, } 2017 & \text { ISSN 0104-5490 }\end{array}$
}




\section{INTRODUÇÃO}

As feiras são definidas como formas de comércio marcadas pela periodicidade e ocorrem, em geral, nos núcleos urbanos. No Nordeste do Brasil, a relevância deste tipo de comércio para a vida sertaneja ocorre, sobretudo, pela possibilidade de concentrar diversas atividades, em específico, a comercialização de produtos provenientes do campo. As feiras são mercados periódicos, formas comerciais que aproximam lugares distantes, áreas rurais marcadas pela precariedade dos meios de transporte (CORRÊA, 2011). As feiras caracterizavam-se pela comercialização de produtos agrícolas tradicionais, sobretudo, a farinha de mandioca, a carne de sol e o feijão, mas também o milho e rapadura que foram por muito tempo os principais alimentos na mesa dos nordestinos. Esses mercados periódicos comercializavam artigos e utensílios feitos artesanalmente, alguns deles produzidos no campo e outros industrializados de baixo custo, a exemplo de utensílios domésticos como panelas e bacias.

As primeiras feiras nordestinas caracterizavam-se, sobretudo, por serem espaços de comércio do gado, tendo grande importância na formação de núcleos de povoamento. Várias cidades tiveram origem com a feira. Conforme aponta Ab'Sáber (2003), cidades do interior nordestino como Campina Grande/PB, Mossoró/RN, Crato/CE, Sobral/CE, Feira de Santana/BA, Caruaru/PE e Garanhuns/PE cresceram pela importância do comércio e movimentação de suas feiras, abastecidas pelas áreas de brejo ${ }^{2}$. De outro modo, os períodos de seca inibiam uma maior produção agrícola no nordeste seco, repercutindo na oferta desses produtos em feiras, mercados e armazéns das cidades. Talvez por isso tenhamos verificado, no período atual, o predomínio do comércio da confecção popular em várias feiras no interior do Nordeste.

Exemplo disso é a cidade pernambucana de Caruaru que se desenvolveu a partir da feira que até hoje se destaca como um marco de formação daquele núcleo urbano. Situada na mesorregião do Agreste e na Microrregião do Vale do Rio Ipojuca, Caruaru tem população de 351.686 habitantes segundo os dados da Estimativa da População em 2016, publicado pelo Instituto Brasileiro de Geografia e Estatística (IBGE). A cidade encontra-se a 130 quilômetros de distância da capital do estado, Recife, tendo as rodovias federais BR-232 e BR-104 como principais acessos. A feira, localizada na área central daquele núcleo urbano, converge para si

\footnotetext{
${ }^{2}$ As áreas de brejo são caracterizadas pela ocorrência de terrenos úmidos como solos férteis e podem ser encontrados tanto nas regiões de cabeceira quanto em ribeiras de vales úmidos. (GUERRA; GUERRA, 2008).

Gonçalves e Holanda, $2017 \quad$ ISSN 0104-5490 72
} 
grande variedade de mercadorias oriundas de várias localidades do agreste e sertão de Pernambuco.

A cidade de Feira de Santana, na Bahia, também surgiu como ponto de encontro e aglomeração de tropas de viajantes que traziam o gado do sertão para ser comercializado ali. $\mathrm{O}$ comércio do gado naquela localidade deu origem à feira e com o desenvolvimento do comércio local surgiu a vila de Feira de Santana dos Olhos D’Água que ascendeu à condição de cidade de Feira de Santana em 1873. Situada entre a zona da mata e o sertão baiano, distante 117 quilômetros da capital baiana, Salvador, Feira de Santana se consolidou como importante praça de comércio localizada no entroncamento de importantes rodovias que fazem a ligação do Sul/Sudeste do país com a região Nordeste (BR-116, BR-101 e BR-324). Atualmente, Feira de Santana é um centro de comando de uma região metropolitana ${ }^{3}$ com população estimada em 622.639 habitantes (IBGE, 2016).

Sobral, no Ceará, é outro exemplo de cidade nordestina que teve origem na feira de gado. O comércio do couro e de carne salgada (Charqueada), juntamente com o cultivo do algodão, já no final do século XIX, firmou, por meio do binômio gado-algodão, a condição de Sobral como centro coletor de produtos vindos do sertão e das serras do oeste cearense (HOLANDA, 2000). O município de Sobral situa-se na mesorregião do noroeste cearense e na microrregião de Sobral, e conta com população estimada em 203.682 habitantes (IBGE, 2016). A cidade está localizada a uma distância de 232 quilômetros da capital Fortaleza cujo acesso se dá pela rodovia federal BR-222 que liga a capital cearense à região norte do país. Recentemente, no ano de 2016, foi criada a Região Metropolitana de Sobral (RMS) composta por 18 municípios ${ }^{4}$.

Este artigo apresenta as primeiras reflexões e resultados na pesquisa intitulada: As feiras de comércio da confecção popular e novas geografias no Nordeste brasileiro, financiada pelo edital Universal do Conselho Nacional de Desenvolvimento Científico e Tecnológico (CNPq). Os trabalhos de campo foram realizados no período de 2015 a 2016 em que foram realizadas visitas exploratórias, de preparação e ajuste de instrumento da pesquisa e concluída com a aplicação de questionários. A pesquisa teve o objetivo de apontar como hipótese de

\footnotetext{
${ }^{3}$ A Região Metropolitana de Feira de Santana - RMFS foi instituída pela Lei Complementar no 35 de 06 de julho de 2011 que versa no seu artigo $1^{\circ}$ que a RMFS, como uma unidade regional do Estado da Bahia, é constituída pelo agrupamento dos Municípios de "[...] Feira de Santana, Amélia Rodrigues, Conceição da Feira, Conceição do Jacuípe, São Gonçalo dos Campos [...]”. (BAHIA, 2011).

${ }^{4}$ A Região Metropolitana de Sobral foi criada pela Lei Complementar n ${ }^{\circ} 168,27$ de dezembro de 2016 , sendo constituída pelo agrupamento dos municípios de Alcântaras, Cariré, Coreaú, Forquilha, Frecheirinha, Graça, Groaíras, Massapê, Meruoca, Moraújo, Mucambo, Pacujá, Pires Ferreira, Reriutaba, Santana do Acaraú, Senador Sá, Sobral e Varjota. (CEARÁ, 2016). 
pesquisa as metamorfoses que vêm ocorrendo nas feiras nordestinas com o predomínio da comercialização de artigos da confecção. Buscou-se apreender o conteúdo dessas transformações na perspectiva da sociedade e do espaço tendo como objeto de pesquisa as feiras de confecção que ocorrem nos municípios de Sobral no Ceará; Caruaru em Pernambuco; e Feira de Santana na Bahia.

Buscou-se expor no primeiro tópico desse artigo, alguns aportes teóricos que nortearam a pesquisa para, posteriormente, apresentar no segundo tópico, os circuitos espaciais da feira de confecção popular que articulam as cidades estudadas tecendo novas redes geográficas no Nordeste brasileiro.

\section{APORTES TEÓRICOS}

O movimento de desconcentração da produção para as regiões periféricas marcou a região Nordeste do país com a vinda de indústrias de grande porte de vários setores (alimentos, bebidas, calçados, etc.). Entretanto, com relação ao incentivo às Micro e Pequenas Empresas - MPE's observou-se, em particular, o setor de confecção como uma atividade que ocupa as comunidades produtoras em distritos rurais. No caso do município de Sobral/CE, houve o estímulo da produção confeccionista de produtos de recém-nascidos que se desenvolveu no distrito de Taperuaba. Identificou-se na figura do atravessador, o controle da circulação da matéria-prima, dos produtos acabados de modo que, muitas vezes, ele próprio é o dono dos estabelecimentos comerciais locais (MONIÉ; HOLANDA, 2001). Todavia, verificou-se que parte da produção confeccionista dos distritos rurais de Sobral e municípios vizinhos (Frecheirinha, Morrinhos e Santa Quitéria) era comercializada na feira do distrito de Aprazível, também situado em Sobral/CE (GONÇALVES; AMORA, 2014).

Para compreender as feiras populares nordestinas utilizou-se de um arcabouço teórico-metodológico que teve como ponto de partida a elaboração de um estado da arte. Assim, de modo breve, revisitou-se os ensinamentos e conceitos formulados por Christaller (1981), Corrêa (1988a; 1988b; 2011), Santos (1994; 2007), Silveira (2004), Arroyo (2008), Pintaudi (2009), Cardoso; Maia (2007) pela relevância com que tratam das questões referentes a temática do comércio e das feiras. No entanto, dado os limites de um artigo científico restringiu-se a revisão conceitual sobre esse tema.

Walter Christaller (1981) formula a Teoria dos Lugares Centrais, em 1933, e ao tratar da geografia das localidades, afirmou que os fatores econômicos são decisivos para a 
criação, desenvolvimento e declínio das cidades, ou seja, a existência de certas regularidades econômicas determinam o tamanho, a distribuição, o número de cidades e sua área de influência. A preocupação, com as relações econômicas e a extensão espacial de suas influências, é demonstrada pelo autor quando afirma que "[...] cada relação econômica e cada evento econômico são, sem exceção, relacionados com o espaço e que a relação espacial é também um elemento constituinte dessas relações [...]" (CHRISTALLER, 1981, p. 5).

O princípio de ordem centralista é evocado por Christaller para mostrar que a praça do mercado de uma cidade medieval, em geral, está localizada no meio da localidade, isto é, no centro e ao redor estão os equipamentos e estabelecimentos urbanos. Essa ordem, para o autor, entretanto, parece estar ausente das jovens e modernas cidades que parecem cada vez mais caóticas e pouco atrativas. Essa ordem de orientação do centro teria deixado de existir? Essa ordem ainda prevalece na cidade moderna? Quais novos aspectos poderiam ser incorporados ao princípio centralista para que continuasse sendo válido para a grande cidade moderna? (CHRISTALLER, 1981).

A formulação de Robert Gradmann sobre a principal vocação de uma cidade, ou seja, a de "[...] ser o centro de seus arredores rurais e mediadora do comércio local com o mundo externo [...]" é retomada por Walter Christaller ao afirmar que essa vocação principal afeta não somente às pequenas cidades rurais, mas também às cidades maiores de "ordem mais elevada" que vão satisfazer as demandas tanto das cidades menores quanto das pequenas cidades. (CHRISTALLER, 1981, p. 23)

Dessa maneira, Christaller vai ampliar e generalizar a formulação de Gradmann afirmando que: “[...] a principal vocação - ou ainda, a principal característica - de uma cidade é ser o centro de uma região." Apesar de haver quase uma sinonímia entre os termos Cidade e Localidade Central, essa característica principal, entretanto, não se restringe apenas às localidades denominadas de cidades, mas também de localidades que são pontos de mercado. Por isso, o autor opta por chamar essas localidades que exercem um papel de centro de região de lugares centrais; (CHRISTALLER, 1981, p. 24).

Esses lugares centrais podem está vinculados a determinadas áreas ou pontos. Ainda segundo Christaller, existem duas formas para distribuir bens ao consumidor. A primeira visa a oferecê-los em um lugar central de modo que o consumidor possa se deslocar até lá. Já a segunda maneira visa transportar os bens e oferecê-los na residência do consumidor. Dessa maneira, podemos inferir que as feiras atuam também de dois modos, isto é, tanto como ponto central que se instala em determinados lugares e passa a concentrar o comércio e reunir 
consumidores de várias localidades vizinhas e mais distantes se deslocam até a feira para comprar produtos. Isso constitui a feira como um lugar central, uma centralidade. Mas a feira também atua como forma de comércio que se repete em determinados lugares com intervalos regulares. O caráter de mobilidade da feira permite que se desloque para áreas remotas, fazendo a mediação como centro distribuidor.

Na geografia brasileira, é Roberto Lobato Corrêa quem primeiro recupera a Teoria das Localidades Centrais, ressaltando a importância do tema da organização espacial na distribuição de bens e serviços. Para ele, apesar “[...] da extensa bibliografia produzida sobre o assunto, muito pouco foi adicionado ao conhecimento da organização espacial dos lugares de distribuição varejista e de serviços." (CORRÊA, 1988a, p. 50). Os estudos realizados até então buscavam apenas verificações empíricas das proposições gerais da teoria de Christaller ou ativeram-se às técnicas alternativas de definição das redes de localidades centrais, ou, ainda, ao planejamento locacional de atividades terciárias.

O avanço do capitalismo para um estágio mais avançado ampliou a escala de atuação da divisão social e territorial do trabalho de modo que é por meio da rede que se articula a produção e o consumo final. A rede geográfica pode ser compreendida como: “[...] 'um conjunto de localizações geográficas interconectadas' entre si 'por um certo número de ligações'." (CORRÊA, 2011, p. 107). As redes são produtos e condições sociais imbuídas dos contextos econômico, social, político e cultural.

Essa rede de distribuição, entre a produção e o consumo, passa a ter grande importância no contexto social e na organização espacial. Para o autor, a organização espacial da distribuição tem como lócus de atuação "[...] as cidades que se interligam através do comércio atacadista, varejista e dos serviços.” (CORRÊA, 2011, p. 18). A diferenciação do consumo de bens e serviços, segundo Corrêa, não se refere somente ao tipo de bens e/ou serviços ofertados, mas também em relação à qualidade e quantidade destes. Considera-se assim que a diferenciação do consumo "[...] entre classes sociais se traduz em uma complexa hierarquia de localidades centrais que assume diferentes arranjos.” (CORRÊA, 2011, p. 22).

A atuação espacial dos estabelecimentos é marcada pela hierarquia das localidades centrais que, por sua vez, é definida por um alcance espacial máximo e alcance espacial mínimo. No que se refere aos estudos das redes de localidades centrais nos países subdesenvolvidos, Corrêa aponta três modos de organização, sejam eles: as redes dendríticas de localidades centrais; os mercados periódicos e os desdobramentos da rede em dois 
circuitos da economia urbana (superior e inferior). Acrescentando que tais redes não são excludentes e podem coexistir em uma rede regional (CORRÊA, 1988b).

A feira nordestina é destacada por Corrêa como um componente da rede de localidades centrais. Para ele, as feiras exercem um papel relevante seja em vilas, pequenas cidades ou até mesmo cidades com grande número de população. Segundo esse autor, quanto maior for a centralidade da cidade, maior será a importância de sua feira seja pelo número de participantes seja pelo raio de influência (CORRÊA, 1988b). Entretanto, pouco se conhece sobre a feira em suas diferentes formas, o que se agrava tendo em vista as mudanças que ocorrem e tendem a transformá-la ou até mesmo extingui-la enquanto forma de comércio (CORRÊA, 2011).

Outra contribuição voltada à essa temática foi, sem dúvida, a Teoria dos Dois Circuitos da Economia Urbana, formulada pelo professor Milton Santos. O mesmo aponta que "[...] a modernização de atividades é simultânea à expansão de formas econômicas menos modernas que abriga uma parcela da 'pobreza' urbana, permitindo a existência de um setor econômico diferenciado do setor de grande capital.”. Ainda para o autor, essas atividades “[...] tanto de fabricação como de serviços, pertenceriam ao que chamamos de Circuito Inferior e Circuito Superior Marginal da economia urbana dos países subdesenvolvidos [...]" (SANTOS, 1994, p. 95).

No que se refere à estrutura e funcionamento dos dois circuitos da economia urbana, Santos (1994) esclarece que o circuito superior surge pela força do mercado, pois detém o domínio da uma produção pouco dependente e em função da própria estrutura econômica e financeira, cria o consumo. Por outro lado, o circuito inferior é dominado por uma produção que atende a "[...] um consumo que não pode ser respondido no circuito superior, esse consumo podendo ter origem em hábitos tradicionais ou ser uma imitação, a partir do próprio circuito superior.”. Há, ainda, o circuito superior marginal que opera segundo os "[...] parâmetros modernos, o que o aproxima do circuito superior, mas é, em grande parte, resposta às necessidades de consumo localmente induzidas, o que o aproxima do circuito inferior" (SANTOS, 1994, p. 96).

No estudo sobre a cidade de Lima, capital do Peru, na década de 1970, Milton Santos mostrou como os fenômenos ligados à modernização produziram concentração econômica, explosão demográfica e macrocefalia urbana resultado das mudanças ocorridas naquele país no pós-guerra. O autor ressalta o papel do circuito inferior da economia urbana de Lima na absorção da produção de médias e pequenas firmas que ofereciam "[...] uma produção 
manufatureira de qualidade inferior, mas mais acessíveis às classes modestas." (SANTOS, 2007, p. 82). Esses produtos, dentre outros, eram oferecidos por formas específicas de comercialização compostas tanto por instalações fixas em mercados cobertos e ao ar livre quanto pelo comércio ambulante instalado no interior e nos arredores dos mercados em aglomerações provisórias de pequenos comerciantes.

Esses dois circuitos econômicos são responsáveis pelo processo de organização espacial nas cidades dos países subdesenvolvidos. Isso infere dizer que da metrópole às cidades locais, ocorrem duas áreas de influência da cidade em que a capacidade de produzir e consumir está diretamente relacionada às forças de modernização que tanto impõem novas realidades quanto se adaptam àqueles herdadas. Com isso, o autor põe em questão a necessidade de se reformular a teoria do lugar central para os países subdesenvolvidos, sobretudo, das noções de limiar e âmbito dada a existência do circuito inferior (SANTOS, 2007).

Silveira (2004, p. 68) assestou que o circuito inferior “[...] é criador de trabalho, mesmo que muitas vezes não possa ser chamado de emprego [...]". Por isso, entendemos que o espaço das feiras de confecções reúne grande quantidade de trabalhadores em torno não somente do comércio da confecção popular, mas também de outros trabalhadores que atuam na montagem e desmontagem da feira, no transporte dos fardos de mercadorias até as barracas, dos vendedores ambulantes dentre outros que utilizam o espaço de comércio da feira como forma de subsistência. A feira enquanto forma de comércio tradicional não escapa às contradições inerentes à relação capital/trabalho.

Essa economia aparentemente invisível dos pequenos está à margem dos circuitos formalizados e, em parte, não tributados. Ela é formada por uma grande quantidade de atores econômicos de porte modesto que ocupam "[...] os interstícios dos grandes negócios, preservando o espaço urbano como um território de cultura, vida e liberdade - uma resposta à segregação social da metrópole capitalista." (ARROYO, 2008, p. 1).

De outro modo, Pintaudi (2009) chama atenção para a relevância da centralidade como conceito na análise do espaço comercial. Para a autora enquanto que o centro urbano permanece como forma a centralidade é mutável, embora haja elementos que indicam sua permanência como o próprio uso e presença das redes técnicas. Para essa autora os hipermercados e shopping centers são exemplos de espaços capazes de criar uma centralidade que não necessariamente é acompanhada da ocupação do seu entorno. Desse modo, ela afirma que "[...] as formas comerciais colaboram com a metamorfose da forma urbana, que se torna 
fluida, atendendo às necessidades da reprodução do capital nesse novo momento histórico." (PINTAUDI, 2009, p. 58).

Santos e Silveira (2001) nos fala que, em contraponto às cadeias de hipermercados, as feiras livres operam com outra forma de distribuição do comércio varejista. Para os autores, seguindo o contexto do Sudeste, estas feiras atuam em uma escala restrita do bairro, baseadas em relações de contiguidade e vizinhança, funcionando sempre com uma frequência semanal. Os autores, entretanto, concordam com Gilmar Mascarenhas de Jesus, quando este afirma em sua dissertação de mestrado ${ }^{5}$ que "[...] as feiras livres são diferentes das feiras regionais, próprias do Nordeste e nas quais se reúnem compradores e vendedores oriundos de áreas distantes [...]” (SANTOS; SILVEIRA, 2001, p. 151).

Conforme Cardoso e Maia (2007, p. 554):

Muito embora a feira seja um elemento comum nas cidades de um modo geral, no Nordeste elas têm uma propriedade ímpar, sendo responsáveis pela dinâmica urbana local. Na verdade, a centralidade exercida por elas é na maioria das vezes o das suas feiras, como é o caso de Caruaru, em Pernambuco, e como por muito tempo o foi em Campina Grande, na Paraíba.

Corrêa (2011, p. 26) afirma que as “[...] mudanças advindas com a penetração desigual do capitalismo, tendem a reestruturar em graus diferentes as classes sociais [...] tanto no urbano como no rural [...]". As observações do autor suscitam novas perspectivas analíticas sobre a realidade das feiras livres no Nordeste brasileiro. As transformações em curso nas feiras também passam por um debate acerca da relação campo-cidade. No contexto de uma sociedade cujo espaço social é perpassado por uma práxis "[...] que nasce na cidade, mas que se expande pelo espaço social como um todo. Nesse processo, cidade e campo são redefinidos pela lógica industrial e subordinados à produção e acumulação capitalistas, perdendo suas características substantivas de origem." (MONTE-MÓR, 2007, p. 99). Nesse sentido as noções de campo e cidade são postas em questão, pari passu a feira como espaço de distribuição e comércio tradicional da produção do campo também é examinada a partir da forte inserção dos produtos da indústria de confecção popular que configura uma nova dinâmica às feiras conforme veremos adiante.

\footnotetext{
${ }^{5}$ O lugar da feira-livre na grande cidade capitalista: conflito, mudança e persistência (Rio de Janeiro - 19641989). 


\section{OS CIRCUITOS ESPACIAIS DA FEIRA DE CONFECÇÃO POPULAR NO NORDESTE}

Em Pernambuco, a especialização produtiva de confecção da sub-região do agreste está concentrada, sobretudo, nas cidades de Caruaru, Santa Cruz do Capibaribe e Toritama, agregando mais sete municípios: Surubim, Brejo da Madre de Deus, Cupira, Taquaritinga do Norte, Belo Jardim, Pesqueira e Passira. Além da fabricação da confecção, a dinâmica econômica da região é marcada pela comercialização em grandes feiras de confecção que envolve produtores e vendedores sulanqueiros ${ }^{6}$ (COUTINHO, s/d, p. 40). Os estudos do SEBRAE/PE sobre a produção da confecção no Agreste pernambucano, também aponta para a importância da feira como importante canal de vendas da confecção produzida pelas micro e pequenas empresas (SEBRAE/PE, 2013).

Na Bahia, a produção confeccionista destaca-se em dois núcleos: a) Feira de Santana e Região e b) Região Metropolitana de Salvador (RMS). Para efeito de recorte espacial de análise desse trabalho buscamos enfatizar o núcleo de Feira de Santana e Região. Em geral, no seguimento de confecções predominam as micro e pequenas empresas que têm grande impacto na absorção de mão de obra. Cerca de $70 \%$ das empresas concentram-se em Salvador e Feira de Santana, 7\% em Jequié e Lauro de Freitas e os 23\% restantes estão dispersos pelo Estado. No núcleo de Feira de Santana e Região, 74\% das indústrias de confecção são classificadas como micros e $24 \%$ como pequenas empresas. A localização geográfica da cidade de Feira de Santana lhe permite atuar como entreposto comercial da região abrangendo outros municípios: Amélia Rodrigues, Coração de Maria, Conceição da Feira, Santo Estevão, São Gonçalo dos Campos, Conceição do Coité, Santa Luz, Serrinha, Tanquinho, Santo Antonio de Jesus e Jequié (BAHIA, 2008). A produção confeccionista de Feira de Santana e região, entretanto, se difunde em feiras tradicionais em cidades da região e entorno.

No Ceará, no intuito de conformar outros mercados, vários produtores passam a comercializar suas mercadorias em feiras mais distantes localizadas em cidades da região noroeste do Estado a exemplo das feiras montadas no distrito de Aprazível em Sobral, na cidade de São Benedito e Ipú e no distrito de Deserto em Itapipoca, conformando um circuito de feiras de confecção como podemos visualizar na figura 1.

\footnotetext{
${ }^{6}$ Os sulanqueiros é a denominação dada aos feirantes de confecção da feira da Sulanca, um setor de comércio de confecção popular no interior da Feira de Carauru/PE. 
Figura 1: Circuito de feiras realizado pelos feirantes de confecção popular.

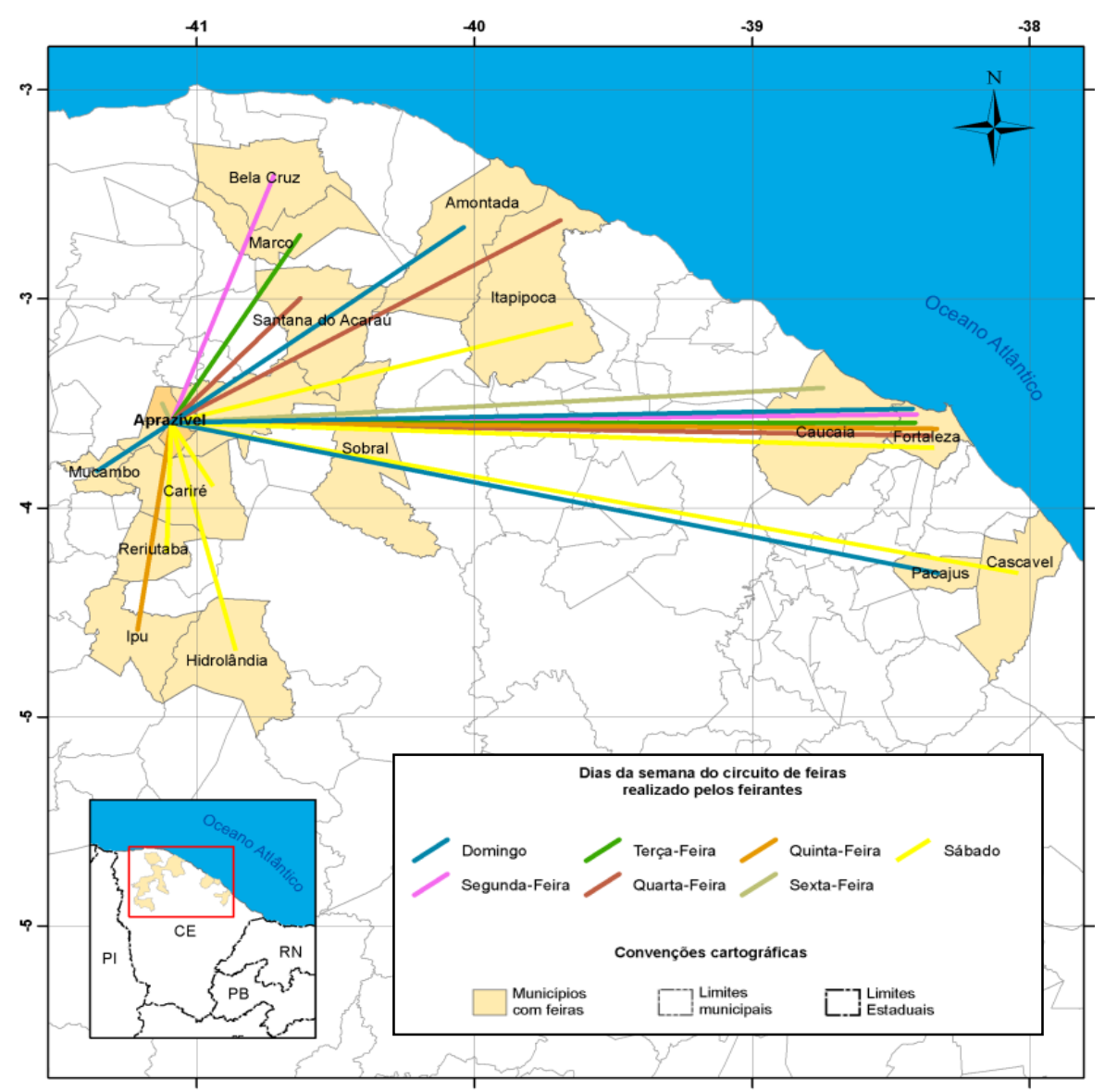

Fonte: Pesquisa direta.

O circuito de distribuição e comércio formado por essas feiras acaba atingindo um público de compradores de várias cidades do oeste cearense e outros municípios da região Norte-Nordeste como Piauí, Maranhão e Pará. Os gêneros vendidos na feira são diversos (jeans, moda praia, moda íntima, infantil, etc.). Seu modo de comercialização ocorre tanto pelo comércio varejista quanto atacadista.

Se observarmos a distribuição geográfica, várias feiras de confecção são montadas: A primeira feira de confecção vai ocorrer sempre na madrugada de quinta-feira na cidade de São Benedito, situada na chapada da Ibiapaba. A montagem das barracas começa, em geral, por volta das três horas da madrugada e a retirada das mercadorias e desmontagem das barracas acontece perto de 11 horas do dia. Para isso vários trabalhadores atuam na montagem e desmontagem das estruturas das barracas bem como carregam fardos de mercadorias em carrinhos que chegam até o espaço da feira. São montadores e carregadores que conformam um subcircuito do trabalho precário. 
A necessidade do deslocamento da mercadoria e dos feirantes que vêm de Fortaleza para a cidade de São Benedito, distante 314 quilômetros da capital, faz com que muitos viajem na quarta-feira para pernoitar ou no distrito de Aprazível em Sobral ou em cidades mais próximas da cidade de São Benedito. Esse processo reforça o papel dos transportes na difusão da feira. São, em média, 20 ônibus que realizam o transporte da mercadoria e dos feirantes para as feiras. Outros, ainda, chegam em carros próprios, enquanto uma pequena parcela utilizam linhas regulares de ônibus intermunicipais para chegarem as cidades onde se realiza a feira de confecção.

A rodovia viabiliza fluidez das mercadorias e pessoas para a feira. $\mathrm{O}$ deslocamento para aquele lugar central tem o objetivo de compra e venda de confecção e não mais o comércio de produtos de campo. As pessoas têm pressa, deve-se chegar cedo, ganhar tempo. Os ônibus e vans têm horário certo de partida por isso é preciso dar conta de todas as compras, pois no retorno para casa ainda são percorrido muitos quilômetros de estrada.

Outra feira de confecção ocorre no mesmo dia, na cidade de Ipu, no período da tarde. Há apenas o intervalo de tempo necessário para o transporte das mercadorias que desce a chapada da Ibiapaba até a cidade de Ipu que fica a 48 quilômetros de distância da cidade de São Benedito. Em Ipu, as barracas são montadas, novamente, tendo início às 15 horas, de modo que a feira vai funcionar de modo pleno somente às 17 horas e se estendendo até às 21 horas.

A terceira feira de confecção acontece na sexta-feira, no distrito de Aprazível em Sobral que está situada no meio-termo do trecho percorrido e dos dias das feiras realizadas. Os feirantes e as mercadorias percorrem, aproximadamente, 96 quilômetros de Ipu até o distrito de Aprazível para iniciar a feira por volta das 04 horas da madrugada indo até cerca de 9 horas. Cabe ressaltar que os feirantes possuem, em cada feira, sua própria barraca onde podem expor sua mercadoria.

A quarta feira de confecção é realizada no sábado no distrito de Deserto em Itapipoca. Aqui, o comércio da feira atinge o público do litoral oeste que chegam em carros de lotações para comprar mercadoria e revender em pequenos distritos e vilarejos litorâneos. A quinta feira de confecção que fecha o circuito vai ser realizada em Fortaleza, no domingo, na feira da rua José Avelino, encerrando o circuito de feiras de confecção. Nesse intervalo, os feirantes repõem seus estoques e/ou adiantam a produção de novas peças para retomar esse circuito na quarta-feira que segue. 


\section{CONSIDERAÇÕES FINAIS}

A partir das reflexões sobre a trajetória espaço-temporal podemos verificar a metamorfose da feira nordestina e também nos permite olhar para as feiras mencionadas nesse trabalho como partes integrantes dos circuitos espaciais da produção da confecção popular. Temos o entendimento de que não é possível pensar a feira e, sobretudo, a feira de confecção sem adentrarmos pelo universo da produção tendo em vista que é na feira onde a produção efetiva da confecção popular se realiza, fazendo-a demandar nova produção. O caráter móvel da feira contribui para a sua dispersão territorial alcançando outros públicos mediante a necessidade criada pelo consumo. Isso também nos permite pensar a feira enquanto um circuito que articula vários lugares e agentes que trabalham na montagem e desmontagem da feira todas as semanas, conformando um subcircuito do trabalho precário composto por montadores e carregadores das estruturas das barracas.

Desse modo, constata-se uma verdadeira metamorfose em sua forma e conteúdo evidenciado pela inserção maciça de produtos da indústria da confecção e vestuário. Em alguns casos essa transformação se dá a partir de feiras já existentes, como as de Ipú e São Benedito, na Serra da Ibiapaba no Ceará. Outras surgem voltadas, exclusivamente, para o comércio da confecção como é o caso das feiras dos distritos de Aprazível e Deserto, pertencentes aos municípios cearenses de Sobral e Itapipoca, respectivamente.

Ao pensar a realidade das feiras de confecção, nos deparamos com a escassez de informações oficiais, bem como, com os limites de uma análise quantitativa para a apreensão da dinâmica desse fenômeno. Forçoso também seria querer dar apenas um tratamento estatístico a questão da produção e comercialização da confecção popular com base formal, tendo em vista um grande número de pequenas unidades produtivas domiciliares que mobilizam o trabalho familiar, sem falar daqueles pequenos produtores que utilizam a feira como estratégia espacial para comercializar sua produção.

\section{REFERÊNCIAS BIBLIOGRÁFICAS}

AB'SÁBER, Aziz Nacib. Caatingas: O Domínio dos Sertões Secos. In.: Os domínios de natureza no Brasil: potencialidades paisagísticas. São Paulo: Ateliê Editorial, 2003. 
ARROYO, Mônica. Novos paradigmas I: a economia invisível dos pequenos. J. Le Monde Diplomatique Brasil. Ed. Bras., A. II, n. 15. Out., 2008. Disponível em: <http://diplomatique.org.br/a-economia-invisivel-dos-pequenos/>. Acesso em: 12 jul. 2017. BAHIA. Secretaria de Ciência Tecnologia e Inovação. Plano de Desenvolvimento do APL de Moda da Bahia. Salvador, 2008.

Lei Complementar $\mathbf{n}^{\mathbf{0}}$ 35, de 06 de julho de 2011. Disponível em: <http://www.saeb.ba.gov.br/vs-arquivos/HtmlEditor/file/estruturaorganizacional/Lei Comprementarn\%C2\%BA35.pdf>. Acesso em: 15 jun.2014.

CARDOSO, Carlos A. de A.; MAIA, Doralice S. Das feiras às festas: as cidades médias do interior do nordeste. In.: SPOSITO, Maria Encarnação Beltrão. (Org.). Cidades médias: espaços em transição. São Paulo: Expressão Popular, 2007.

CEARÁ. Lei Complementar $\mathbf{n}^{\mathbf{0}}$ 168, de 27 de dezembro de 2016. Dispõe sobre a criação da Região Metropolitana de Sobral, cria o Conselho de Desenvolvimento e Integração da Região Metropolitana de Sobral. Disponível em: <http://imagens.seplag.ce.gov.br/PDF/20161228/do20161228p01.pdf. $>$ Acesso em: 10 jul. 2017.

CHRISTALLER, Walter. Os lugares Centrais na Alemanha do Sul. Uma pesquisa de geografia econômica acerca da regularidade da distribuição e do desenvolvimento das localidades com funções urbanas. Trad. Mário Antônio Eufrásio. Versão Preliminar. São Paulo, 1981.

CORREAA, Roberto Lobato. Trajetórias geográficas. 6 ed. Rio de Janeiro: Bertrand Brasil, 2011.

. Repensando a teoria das localidades centrais. In: SANTOS, Milton (Org.) Novos rumos da geografia brasileira. 2 ed. São Paulo: HUCITEC, 1988a.

A rede de localidades centrais nos países subdesenvolvidos. R. bras. Geogr. Rio de Janeiro. ano 50, n.1, p. 61-83, jan./mar. 1988b.

COUTINHO, Lúcia M. G. (Coord.). Análise do Mapeamento e das Políticas para Arranjos Produtivos Locais no Norte, Nordeste e Mato Grosso e dos Impactos dos Grandes Projetos Federais no Nordeste. Nota Técnica 02. Arranjos produtivos locais no estado de Pernambuco: mapeamento, metodologia de identificação e critérios de seleção para políticas de apoio. Pernambuco. Redesist, s/d. Disponível em: <http://www.politicaapls.redesist.ie.ufrj.br/documentos>. Acesso em: 24 abr. 2014.

GONÇALVES, Luiz Antonio Araújo.; AMORA, Zenilde Baima. As metamorfoses da feira nordestina e os circuitos espaciais da confecção popular no estado do Ceará. In: CONGRESSO BRASILEIRO DE GEÓGRAFOS, 7., 2014, Vitória. Anais. Vitória/ES. 2014.

GUERRA, Antonio Teixeira; GUERRA, Antônio José Teixeira. Novo dicionário Geológico-Geomorfológico. 6 ed. Rio de Janeiro: Bertrand Brasil, 2008.

HOLANDA, Virgínia Célia Cavalcante de. Dinâmica sócio-espacial de uma cidade média Sobral-CE. 2000. 123 f. Dissertação (Mestrado em Geografia) - Centro de Ciências e Tecnologia, Universidade Estadual do Ceará. Fortaleza, 2000.

INSTITUTO BRASILEIRO DE GEOGRAFIA E ESTATÍSTICA - IBGE. Estimativas da população residente no Brasil e unidades da federação com data de referência em 01/07/2016. Disponível em: $<$ ftp://ftp.ibge.gov.br/Estimativas_de_Populacao/Estimativas_2016/estimativa_dou_2016_20 160913.pdf>. Acesso em: 06 jul. 2017.

MONIÉ, Frédéric.; HOLANDA, Virgínia Célia C. Redes técnicas e redes sociais: problemáticas do desenvolvimento local integrado e sustentável. Estudo de caso $\mathrm{n}^{\circ} 3$. Reestruturação produtiva, desconcentração Industrial e desenvolvimento local: 
Modernização, taylorização do território e políticas públicas inovadoras no município de Sobral, Ceará. Relatório final de pesquisa. LABTeC/ UFRJ - NEURB/ UVA, 2001.

MONTE-MÓR, Roberto L. Cidade e campo, urbano e rural, o substantivo e o adjetivo. In: FELDMAN, Sarah; FERNANDES, Ana. (Orgs.). O urbano e o regional no Brasil contemporâneo: mutações, tensões, desafios. Salvador: EDUFBA, 2007.

PINTAUDI, Silvana Maria. Anotações sobre o espaço do comércio e do consumo. In: CARRERAS, Carles.; PACHECO, Suzana Mara M. (Orgs.). Cidade e Comércio: a rua comercial na perspectiva internacional. 1 ed. Rio de janeiro: Armazém das letras, 2009.

SANTOS, Milton. Por um a economia política da cidade: o caso de São Paulo. São Paulo: Editora HUCITEC, 1994.

Economia espacial: críticas e alternativas. Trad. Maria Irene de Q. F. Szmrecsányi. 2 ed. 1 reimpr. São Paulo: Editora da Universidade de São Paulo, 2007. (Coleção Milton Santos; 3)

SANTOS, Milton.; SILVEIRA, Maria L. O Brasil: território e sociedade no início do século XXI. Rio de Janeiro/São Paulo: Editora Record, 2001.

SERVIÇO DE APOIO ÀS MICRO E PEQUENAS EMPRESAS DO ESTADO DE PERNAMBUCO - SEBRAE/PE. Estudo Econômico do Arranjo Produtivo Local de Confecções do Agreste Pernambucano. Relatório final. Recife, Maio de 2013.

SILVEIRA, Maria Laura. São Paulo: os dinamismos da pobreza. In: CARLOS, Ana Fani A.; OLIVEIRA, Ariovaldo Umbelino de. (Orgs.). Geografias de São Paulo-1. Representação e crise da metrópole. São Paulo: Contexto, 2004. 